Check for updates

Cite this: RSC Adv., 2019, 9, 28451

Received 18th July 2019

Accepted 19th August 2019

DOI: $10.1039 / c 9 r a 05513 d$

rsc.li/rsc-advances

\section{Forming pure shaped ZSM-5 zeolite bodies by a steam-assisted method and their application in methanol to aromatic reactions}

\author{
Junwen Wang, (D) a Xiaofeng Gao, ${ }^{b}$ Guoliang $C^{a}{ }^{a}$ and Chuanmin Ding (D) *a
}

For an industrial-scale catalytic process with a fixed or packed bed reactor, powder catalysts are not suitable because they may block the reaction pipe and increase the pressure of the reactor. Therefore, catalyst molding is essential for the industrial application of a catalyst. During the catalyst molding, binders are employed as indispensable additives that can achieve the mechanical strength requirements for industrial applications. However, the addition of binders may cover the activity sites of the catalyst and suppress the mass transfer of the reactants and products. So, traditional processes of catalyst molding significantly affect the catalytic performance. In this study, we proposed a vapor-phase-treatment to synthesize a pure shaped ZSM-5 zeolite with the re-crystallization of the binder incorporated silica sol and aluminum nitrate, which were converted into a part of ZSM-5 on a commercial H-ZSM-5 zeolite substrate. Subsequently, the shaped ZSM-5 catalyst was evaluated using the catalytic conversion of methanol to an aromatic (MTA reaction). The results showed that compared to the EPHZ catalyst, the SPHZ catalyst exhibited a long lifetime with a relatively high shape selectivity for methanol and aromatics. To rationalize these results and establish a structure-activity relationship, the zeolite catalysts were thoroughly characterized by XRD, $\mathrm{NH}_{3}-\mathrm{TPD}, \mathrm{FT}-\mathrm{IR}, \mathrm{N}_{2}$ adsorption, TG, SEM, TEM, ICP and AI MASNMR. The results demonstrated that an interesting intra-particle pore structure was formed within the monoliths of the SPHZ catalyst. Moreover, the superior catalytic performance obtained for SPHZ may have also been due to the broad acid strength distribution and the conversion of the silicon aluminum adhesive agent to zeolite crystals.

\section{Introduction}

Aromatics, such as benzene (B), toluene (T) and xylene (X), are key components in valuable organic chemicals that mostly rely on petrochemical processes, such as cracking of naphtha. With the consumption of fossil resources and the increase in demand for transport fuels, traditional petrochemical production processes cannot meet the needs of the market. Therefore, the search for a non-petroleum route has become one of the important issues in contemporary society. ${ }^{1,2}$ The methanol to aromatic (MTA) conversion technology has gained increasing attention as an important process for utilizing surplus industrial methanol because methanol can be easily acquired via the hydrogenation of CO. ZSM-5 zeolite has been the focus of many recent studies and is still the most promising catalyst used to achieve the above conversion owing to its strong Brønsted acid sites, elevated specific surface area and well thermal and

${ }^{a}$ College of Chemistry \& Chemical Engineering, Taiyuan University of Technology, Taiyuan 030024, P. R. China. E-mail: dingchuanmin@tyut.edu.cn; Fax: +860351 6014 498; Tel: +8603516014498

${ }^{b}$ School of Chemistry and Chemical Engineering, Liaocheng University, Liaocheng 252000, P. R. China hydrothermal stabilities. ${ }^{3}$ In addition, the sole micropore construction of ZSM-5 zeolite containing intricate network channels is a diffusional limitation that prevents access to the active sites and the catalytic conversion of bulky molecules. Carbonaceous residue and deposition often lead to serious diffusion limitations and a rapid inactivation rate.,5 Extensive research have been devoted to improve the accessibility in zeolite with the purpose of circumventing the diffusion limitations and taking the advantage of its built-in micropores. Two fundamental strategies can be adopted: (1) increasing the width of the micropores by introducing controlled mesopores or macropores that are linked to the zeolitic micropores. Wang et al. synthesized Zn-ZSM-5 mesopores by an one-step desilication and reassembly method. ${ }^{6,7}$ (2) Reducing the crystallization size of the catalyst can increase the surface area and shorten the diffusion pathlength. Compared with large crystallites, nano-crystal zeolite exhibited a long lifetime and high aromatics in the conversion of methanol to hydrocarbons. ${ }^{8}$

However, all the above efforts mainly focused on zeolite powder rather than the shaped catalysts. For industrial scale applications, extrusion is the necessary step for the transition from powder to a technical body. A few academic studies that are related to the extrusion process have been widely neglected 
up to date. ${ }^{9-12}$ Although the vast majority of this knowledge comes from pure zeolite powder, the effect of shaping is still unknown. The extrusion process will add matrix materials that usually include natural clay, alumina or/and silica to gratify the mechanical, attrition resistance and thermal stability. They can exhibit beneficial or deleterious impacts on the catalyst reaction. However, the binders and other matrix materials are inert components for the catalyst in our subconscious mind. The physical and chemical effects of the extrusion process are the following: the modification of mass transfer characteristics, modification of porosity characteristics and improvement in the attrition strength. Their role is worthy of greater consideration than has hitherto been the case..$^{\mathbf{1 3 4}}$

Nevertheless, the process of compaction has a positive or adverse effect on the given system. When the catalyst was extruded with alumina binder, the ion-exchange ability and acid-catalytic activity of high-silica ZSM-5 were significantly enhanced as reported by Chang. ${ }^{15}$ Both, the external and intracrystalline acidity of the catalyst decreased due to the addition of a silica binder at a concentration of $10 \%$ or $50 \%$. The increased mass transfer efficiency needs to weaken the influence from the added silica binder and exert a positive impact on the acid catalytic activity of the added aluminum binder. It is a challenge to kill two birds with one stone: one challenge is to achieve the molding purpose, and the other is to eliminate the binder residue on the catalyst surface. Recently, Zhou et al. ${ }^{16}$ only utilized silica sol as binders for a successful, organic template, steam-assisted recrystallization after the extrusion process. It was discovered that a superior activity, higher propylene selectivity, and a significantly longer life-span in the MTH reaction as well as the catalytic cracking of the $\mathrm{C} 4$ olefin propylene production were achieved. There existed a problem that the crystallization of the silica species into pure silica zeolite eliminated the effect of the residue matter on the mass transfer efficiency. However, the pure silica species did not affect the acidity. It is worth investigating how to transform silica species into a zeolite phase with activated species during the recrystallization process. In this present study, we achieved the conversion from the binder phase to the crystalline zeolite phase for activated sites on the surface of the catalyst by adopting added silica sol and a small amount of alumina nitrate as the binder. The finished products were employed in the MTA (methanol to aromatics) technology. The catalytic performance and catalytic lifetime are discussed in detail.

\section{Experimental section}

\subsection{Catalyst preparation}

The fabrication of the re-crystalline catalyst was achieved in two key processes: shaping and steam-assisted re-crystallization of the aluminosilicate species. Commercially available H-ZSM-5 $\left(\mathrm{SiO}_{2} / \mathrm{Al}_{2} \mathrm{O}_{3}=70\right)$ was obtained from the NanKai University Zeolite Ltd. In order to alter the properties of zeolite, quantitative aluminium nitrates $(0.226 \mathrm{~g})$ were added to the pristine zeolite powder $(20 \mathrm{~g})$ before mixing with $10 \mathrm{~mL}$ silica solution (mass fraction of $30 \%$ ). The $\mathrm{SiO}_{2} / \mathrm{Al}_{2} \mathrm{O}_{3}$ ratio in the binder was approximately 50. Alumina nitrate was mixed with zeolite powder; thereafter, the silica solution was added to this strongly blended mixture. After extrusion, the uniform body was dried at 373 K overnight. We labeled the product as EPHZ, where the "E" in the catalyst name that stands for "extrudate", the "P" means "process" and the "HZ" denotes the "H-ZSM-5". SPHZ was prepared by employing EPHZ as a raw material and the " $\mathrm{S}$ " in the catalyst name meant "steam". A simple self-made device with a wire of 40 meshes was employed to achieve aluminosilicate species in the re-crystallization process. The device was placed in the middle of a Teflon-lined steel autoclave to make the steam pass from the bottom of Teflon container. EPHZ (10 g) was placed above the wire, and then the mixed solution of $n$ butylamine $(10 \mathrm{~mL})$ and distilled water $(20 \mathrm{~mL})$ was added to the bottom of the autoclave, which was transferred to a blast oven and heated at $443 \mathrm{~K}$ for $72 \mathrm{~h}$. The solution was then filtered and washed with de-ionized water until neutral. The product was dried at $373 \mathrm{~K}$ for $12 \mathrm{~h}$ and calcinated at $823 \mathrm{~K}$ for $6 \mathrm{~h}$ under air flow. To achieve the conversion from the $\mathrm{Na}$ form to the $\mathrm{H}$ form, all samples were ion-exchanged with an aqueous $\mathrm{NH}_{4} \mathrm{NO}_{3}$ solution $(1 \mathrm{M})$, and then calcinated at $823 \mathrm{~K}$ for $6 \mathrm{~h}$. The obtained product was designed as SPHZ. To get a real opinion of the experimental procedure, compression molding was used to shape HZSM-5.

\subsection{Catalyst characterization}

$\mathrm{X}$-ray diffraction (XRD) with $\mathrm{Cu} \mathrm{K} \alpha$ radiation was employed to identify the phase and calculate the crystallinity of the samples at $40 \mathrm{kV}$ and $40 \mathrm{~mA}$. The patterns in the range of $5-50^{\circ}$ with a scanning speed of $8^{\circ} \min ^{-1}$.

Scanning electron microscopy (SEM) images were recorded on a HITACHI SU-8010 microscope at $10 \mathrm{kV}$ for investigating the morphology and crystal size of the samples. Transmission electron microscopy (TEM) images were recorded using a Tecnai G2 F20 instrument operating at $200 \mathrm{kV}$.

Nitrogen adsorption-desorption isotherms were measured on a Micromeritics ASAP 2020 instrument at $77 \mathrm{~K}$. Prior to the measurement, the samples were degassed at $573 \mathrm{~K}$ under high vacuum for $4 \mathrm{~h}$. The specific surface area was calculated using a BET model. The total pore volumes were calculated using the nitrogen adsorbed volume at a relative pressure of 0.99 .

Solid state nuclear magnetic resonance with magic angle spinning (MAS NMR) was used to investigate the coordination of the $\mathrm{Al}$ atoms in the ZSM-5 framework. The measurements were performed on a Bruker DSX 300 wide-bore. The NMR spectrometer was equipped with two radio frequency (rf) channels and a spin speed of $15 \mathrm{kHz}$ with $2.05 \mathrm{~s}$ intervals between the successive accumulations. The ${ }^{27} \mathrm{Al}$ chemical shifts were reported relative to the $\mathrm{Al}\left(\mathrm{H}_{2} \mathrm{O}\right)_{6}{ }^{3+}$ solution.

Temperature programmed desorption measurements for $\mathrm{NH}_{3}\left(\mathrm{NH}_{3}\right.$-TPD) were performed on a micromeritics An auto chem TP5076 instrument was used for monitoring the amount and type. The sample ( $0.1 \mathrm{~g}$, particle size: $20-40$ meshes) was first pretreated at $600 \mathrm{~K}$ for $1 \mathrm{~h}$ under a flow of $\mathrm{He}$, cooled to 293 $\mathrm{K}$ and blown with ammonia for $30 \mathrm{~min}$ to saturation. Then, the physically absorbed content was removed by switching the flowing gas to pure $\mathrm{He}$ for $2 \mathrm{~h}$. Finally, the temperature 
programed desorption of chemically absorbed $\mathrm{NH}_{3}$ was conducted by raising the temperature at a rate of $10 \mathrm{~K} \mathrm{~min}^{-1}$ at 373 $\mathrm{K}$ for $873 \mathrm{~K}$.

Brønsted acid sites and Lewis acid sites were determined using a WQF-510 Fourier transform infrared (FT-IR) spectroscope with a resolution of $4 \mathrm{~cm}^{-1}$. For IR analysis, the selfsupported wafer was extruded from sample powder. A $1: 300$ $\mathrm{KBr}$ /adsorbed pyridine mass ratio was used at $60{ }^{\circ} \mathrm{C}$ for 30 minutes and then $200{ }^{\circ} \mathrm{C}$ for 20 minutes.

Thermogravimetric analysis (TGA) was performed on a Setaram Labsys TG-DTA/DSC 1600 instrument to detect the amount of coke formed on the used catalyst surface. The sample was raised from $300 \mathrm{~K}$ to $973 \mathrm{~K}$ with a speed of $10 \mathrm{~K} \mathrm{~min}^{-1}$ in the air. The weight loss of the catalyst was detected with the increase in temperature.

\subsection{Catalyst evaluation}

The as-prepared catalyst performance was evaluated for the MTA reaction in a continuous-flow fixed bed reactor at atmospheric pressure. Prior to the reaction, a ceramic ring of 10-20 meshes and 20-40 meshes was installed from the outside to the inside of the catalyst on both sides. HZSM-5 (10 g) with 20-40 meshes was placed in the middle of the pipe. Feed methanol liquid was supplied by a plunger pump at a flow rate of 0.2 $\mathrm{mL} \min ^{-1}$, and the reaction temperature was maintained at 673 $\mathrm{K}$ by a K-type thermocouple, which was placed into the center of the catalyst bed. After the reaction, the reaction products were passed through a gas/liquid separator at $273 \mathrm{~K}$. Then, the gas fraction was analyzed on-line using a GC920 equipped with a thermal conductivity detector (TCD), and the liquid hydrocarbons were analyzed using a GC950 equipped with a capillary column and a flame ionization detector (FID).

\section{Results and discussion}

\subsection{Characterization}

The commercial zeolite powder, the shaped zeolite with aluminosilicate species as the binder and the zeolite from the binder particle recrystallization were designed as HZSM-5, EPHZ and SPHZ, respectively. The X-ray diffraction patterns of the parent and modified catalyst are displayed in Fig. 1. It can be seen that all of the ZSM-5 samples exhibited a well-resolved diffraction in the range of $8-10^{\circ}$ and $22-25^{\circ}$, which were consistent with the reported MFI crystal structure. ${ }^{17}$ As directly perceived by the senses, SPHZ had the highest diffraction peak intensity. In order to further discuss the crystallinity degree difference for these samples, the crystallinity degree of HZSM-5 was used as a reference. For the wide and weak diffraction peak of EPHZ, its relative crystallinity had a sharp decline. The weak peak intensity of EPHZ may have come from the low percentage of ZSM-5 zeolite due to the damage of the zeolite skeleton in the extrusion process that can be ignored. It was easy to see that the crystallinity degree of SPHZ greatly increased. During the organic template steam-assisted recrystallization process, the aluminosilicate species translated the species into a zeolite phase that elevated the degree of crystallization. This result was

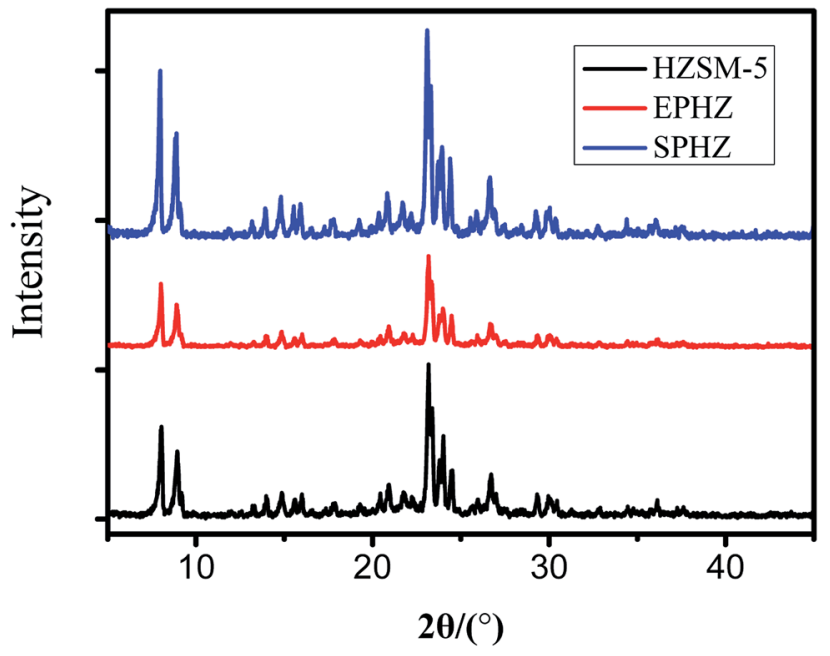

Fig. 1 XRD pattern of the catalyst samples.

further confirmed by the SEM image as a few silicon binders were observed.

Scanning electron microscopy (SEM) was utilized to further demonstrate the structure and morphology of the above catalyst. As shown in the display in Fig. 2(a) and (b), the commercially-available parent ZSM-5 has a sharp surface with a typical uniform hexagonal shape. After the extrusion process, the ordered structure of zeolite disappeared and ZSM-5 was surrounded by numerous binders to form a block in Fig. 2(c) and (d). The silicate species of the binders restrained the access of the raw material to the zeolite active sites in that the shaped catalyst was almost covered by the binders. Similar crystallographic texture morphologies in Fig. 2(e) and (f) were observed. At the same time, the adhesive particles almost completely disappeared and only the zeolite crystals still existed, which suggested that the majority of the aluminosilicate species were translated into zeolite crystals. ${ }^{\mathbf{1 8}}$

Fig. 3 shows evident structural differences among EPHZ and SPHZ by TEM characterization. The entire uniform crystallinity of the EPHZ sample (Fig. 3(a)) was covered by the binders. This seriously affected the mass transfer efficiency and changed the acid distribution, which was in accordance with the $\mathrm{N}_{2}$ adsorption and the $\mathrm{NH}_{3}$-TPD consequence. At the same time, there was no evident large spot observed for the EPHZ sample. For the SPHZ sample (Fig. 3(b)), no additional aluminum nitrate particles were observed, indicating that aluminum nitrate was successfully transformed to zeolite in the course of the recrystallization process. As we can see, there are numerous white dots around the crystal lattice, which indicated that the removal of the silicon species in the skeleton by alkali vapor led to lattice defects that resulted in the mesoporous or even hollow structure. ${ }^{19}$

As shown in the ${ }^{27} \mathrm{Al}$ solid-state MAS NMR spectra in Fig. 4, the small peak detected at 0 ppm was attributed to the octahedral aluminum species of HZSM-5 and SPHZ. EPHZ exhibited a relatively high resonance at $0 \mathrm{ppm}$, which demonstrated that the majority of aluminum nitrate was in the form of non- 

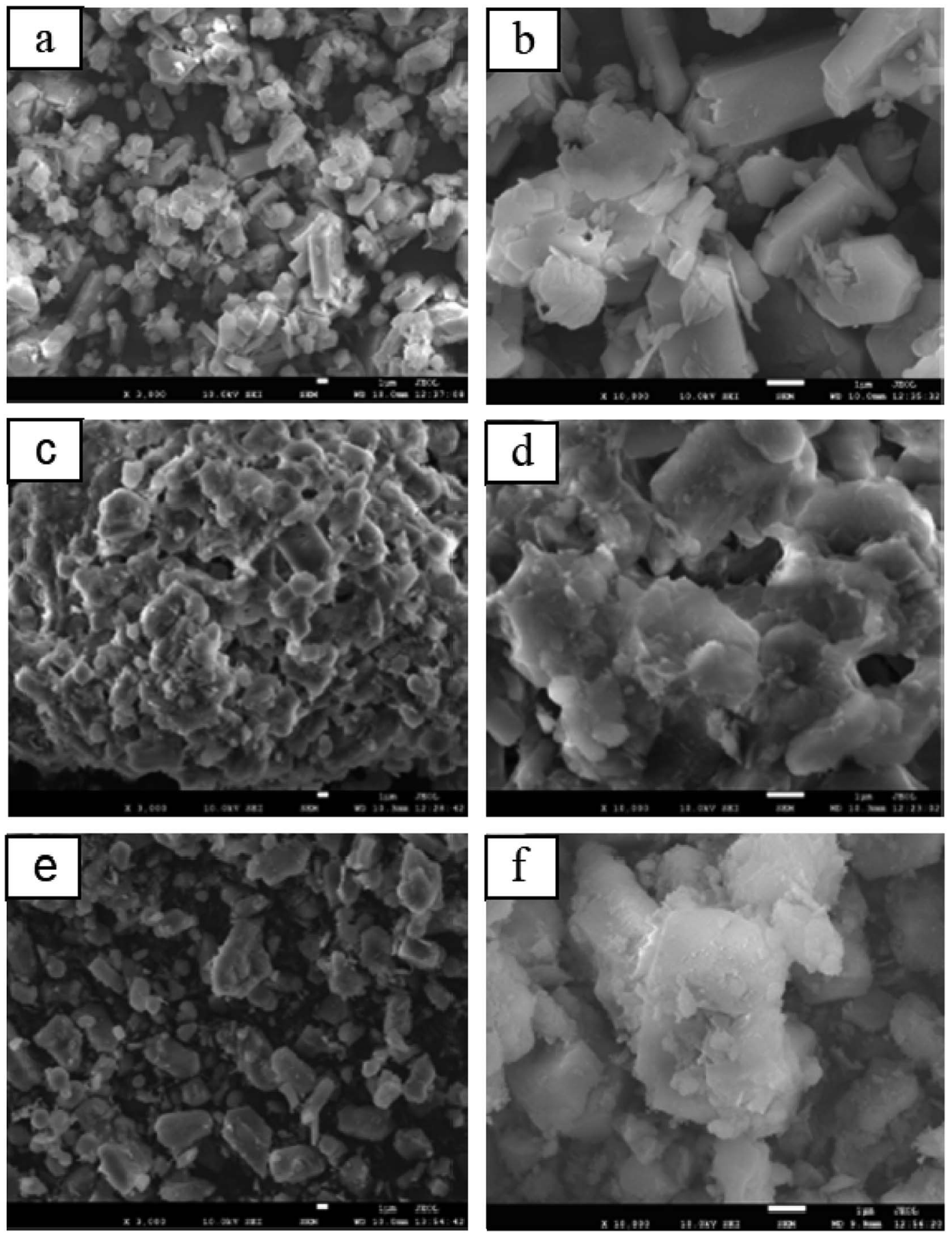

Fig. 2 SEM images of HZSM-5 ( $a$ and b), EPHZ (c and d) and SPHZ (e and f).

framework aluminum species. After the steam-assisted process, some of the extra aluminum framework was transformed into the aluminum skeleton. The three samples indicated a relatively sharp resonance at $56 \mathrm{ppm}$, which was assigned to tetrahedral aluminum species in the zeolite framework. The above characterization results confirmed that all of the zeolite had a highly crystalline aluminosilicate structure with MFI frameworks. The resonances of the three samples at $56 \mathrm{ppm}$ were in the order of SPHZ > HZSM-5 > EPHZ. The EPHZ framework had the lowest aluminum framework peak, which indicated that the decrease in the catalyst proportion affected the peak height of the aluminum skeleton. After the steam-assisted process, there were two main factors that affected the peak for SPHZ: the conversion of the binder increasing the proportion of the catalyst and that the aluminosilicate species transformed into a crystalline phase, which increased the skeleton of aluminum.

The $\mathrm{N}_{2}$ adsorption-desorption isotherms also demonstrated the structural and textural properties of the catalysts as shown 

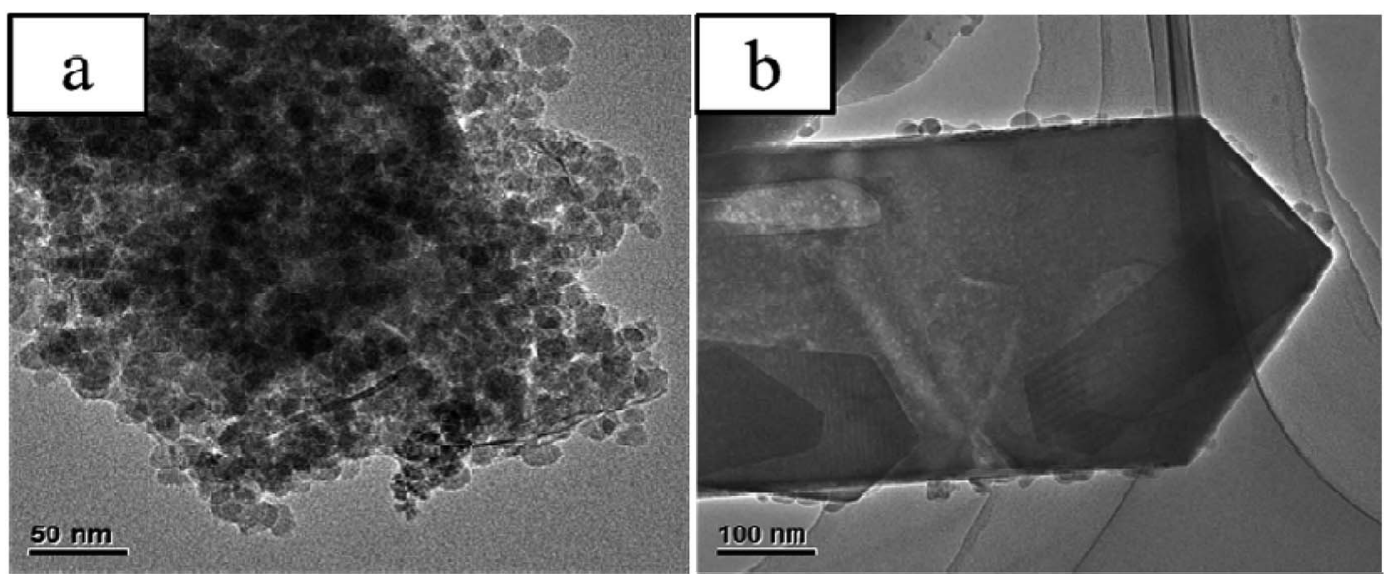

Fig. 3 HRTEM images of EPHZ (a) and SPHZ (b).

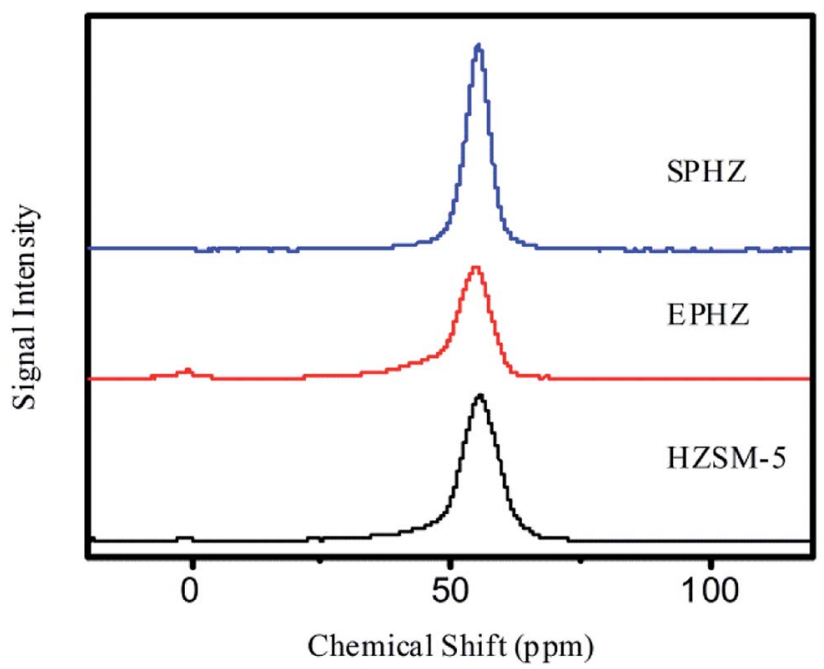

Fig. 4 Al MAS NMR spectra images of HZSM-5, EPHZ and SPHZ.

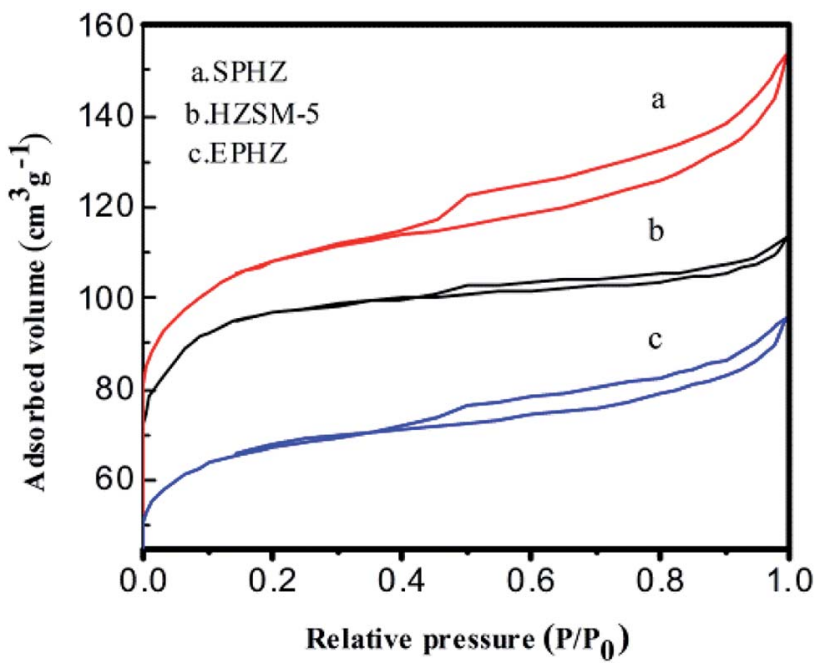

Fig. $5 \quad \mathrm{~N}_{2}$ - adsorption-desorption isotherms of HZSM-5, EPHZ and $\mathrm{SPHZ}$. in Fig. 5. The surface areas and micropore volumes for these catalysts are shown in Table 1 . HZSM-5 displayed type I isotherms with a sharp uptake, which indicated that the HZSM5 micropores were filled with molecular ammonia in the lowpressure region, suggesting that the pristine zeolite microcrystal was a micropore-dominant zeolite. ${ }^{20}$ The surface area of HZSM-5 was $366 \mathrm{~m}^{2} \mathrm{~g}^{-1}$ in total, where $90 \mathrm{~m}^{2} \mathrm{~g}^{-1}$ belonged to the external surface. The total pore volume of HZSM-5 was $0.17 \mathrm{~mL} \mathrm{~g}^{-1}$, which included $0.11 \mathrm{~mL} \mathrm{~g}^{-1}$ and $0.06 \mathrm{~mL} \mathrm{~g}^{-1}$ for the micropores and stacking pores, respectively. Compared with the HZSM-5 catalyst, the surface area of the EPHZ catalyst decreased to $251 \mathrm{~m}^{2} \mathrm{~g}^{-1}$, which may have been due to the binder covering the surface of the HZSM-5 catalyst. However, the mesopore volume increased to $0.08 \mathrm{~cm}^{3} \mathrm{~g}^{-1}$. A large number of mesopores were produced during the operation of catalyst molding. For SPHZ zeolite, the external surface area reached $359 \mathrm{~m}^{2} \mathrm{~g}^{-1}$ and the mesopore volume was $0.09 \mathrm{~cm}^{3} \mathrm{~g}^{-1}$. The SPHZ sample showed more obvious hysteresis loops, mainly due to alkali desilication. Thus, mesoporous intracrystalline was formed.

The surface amount and strength of the $\mathrm{H}$-form zeolite acid type were determined by the temperature programmed desorption of ammonia ( $\mathrm{NH}_{3}$-TPD) characterization, as presented in Fig. 6. All three samples exhibited two well-resolved typical desorption peaks. The temperature regions $440-470 \mathrm{~K}$ and $620-670 \mathrm{~K}$ were referred to the low temperature and high temperature peaks, respectively. ${ }^{21}$ However, the lowtemperature peak was ascribed to weakly acidic silanol groups that covered the catalyst surface, which were reduced by extending the evaluation time. The weak adsorption sites were inactive for the MTA reaction. Therefore, we mainly concentrated on the change in the high-temperature peak. As can be seen, the intensity of the high temperature desorption peak of EPHZ dramatically decreased after the extrusion process, which indicated that the acid sites on the surface of the catalyst were heavily covered. Obviously, the zeolite recrystallization displayed the highest desorption peak due to the disappearance of the silicate binder coverage over the catalyst surface and the generation of the small grain zeolite increasing the acid sites on 
Table 1 Textual properties of HZSM-5, EPHZ and SPHZ

\begin{tabular}{|c|c|c|c|c|c|c|c|c|}
\hline Sample & $\begin{array}{l}\text { Total Al content } \\
\left(\mathrm{mg} \mathrm{L}^{-1}\right)\end{array}$ & $S_{\mathrm{BET}}\left(\mathrm{m}^{2} \mathrm{~g}^{-1}\right)$ & $S_{\text {micro }}\left(\mathrm{m}^{2} \mathrm{~g}^{-1}\right)$ & $S_{\text {meso }}\left(\mathrm{m}^{2} \mathrm{~g}^{-1}\right)$ & $V_{\text {total }}\left(\mathrm{cm}^{3} \mathrm{~g}^{-1}\right)$ & $V_{\text {micro }}\left(\mathrm{cm}^{3} \mathrm{~g}^{-1}\right)$ & $V_{\text {meso }}\left(\mathrm{cm}^{3} \mathrm{~g}^{-1}\right)$ & $\begin{array}{l}\text { Radial grain crushing } \\
\text { strength }(N / \text { particle })\end{array}$ \\
\hline HZSM-5 & 2.26 & 366 & 276 & 90 & 0.17 & 0.11 & 0.06 & 44.6 \\
\hline SPHZ & 2.32 & 359 & 273 & 86 & 0.19 & 0.10 & 0.09 & 43.1 \\
\hline
\end{tabular}

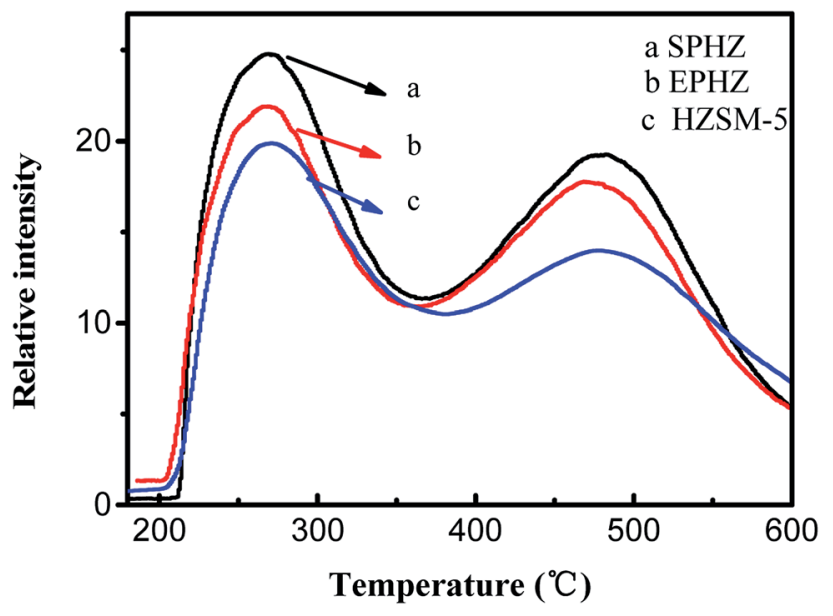

Fig. $6 \mathrm{NH}_{3}-\mathrm{TPD}$ profiles of HZSM-5, EPHZ and SPHZ.

the surface of the catalysts. There were huge acidic differences between EPHZ and SPHZ, which indicated that the effect of acidity on the performance could not be ignored between the samples.

The type and concentration of the Brønsted and Lewis acid sites for the HZSM-5, EPHZ and SPHZ samples were determined by Py-IR at a desorption temperature of $200{ }^{\circ} \mathrm{C}$. The result is depicted in Fig. 7. The peaks at 1540 and $1450 \mathrm{~cm}^{-1}$ corresponded to pyridine interacting with the Brønsted and Lewis acid, ${ }^{22}$ respectively. Moreover, the peak at $1490 \mathrm{~cm}^{-1}$ was ascribed to both Brønsted and Lewis acids. Apparently, the

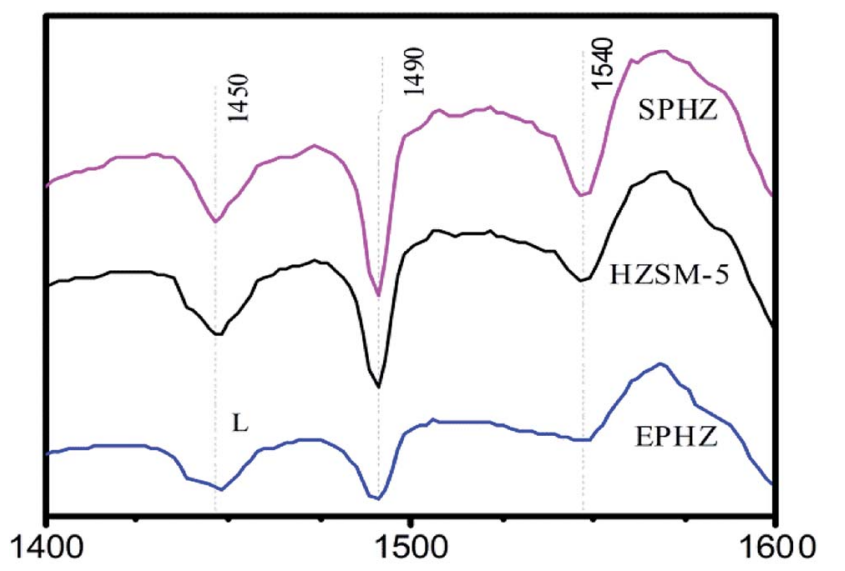

Wave number $\left(\mathrm{cm}^{-1}\right)$

Fig. 7 FT-IR spectra of the catalyst samples. relative amount of the Brønsted acids for the different samples was as follows: SPHZ > HZSM-5 > EPHZ. After the molding process, the total number of acid sites markedly decreased for $\mathrm{NH}_{3}$-TPD, as shown in Fig. 6 . The $\mathrm{L}$ acid sites and $\mathrm{B}$ acid sites exhibited the same trend. In fact, the trend was more likely due to the binder covered or even encapsulated the catalyst that affected the acidity of the catalyst. This result suppressed the diffusion of the pyridine molecules. At the same time, SPHZ exhibited the highest B acid sites, which may have been due to the effects of the ordered structure after the steam-assisted procedure and newly grain zeolite crystals were produced.

Built on the above discussion and in previous studies, we showed the formation of full-crystalline monolithic zeolite in the form of schematics in Fig. 8. First, saturated SDA steam condensed into a liquid phase at the top of the reactor and the liquid then dispersed around the catalyst. Silica sol and aluminum nitrate were dissolved by the binder. Meanwhile, the catalyst formed mesopores under alkali vapor. With the dissolved silica sol as the silicon source, the dissolved aluminum nitrate as the aluminum source as well as the condensed SDA as the basic source and structural guide agent, tiny grains catalyst began to form. Finally, the regular catalyst formed around the near-no binder with a large number of intercrystalline mesopores. At the same time, the catalyst crystal increased to some extent after the recrystallization process. This was consistent with the results of transmission electron microscopy.

\subsection{Catalytic performance of the catalysts}

Based on the above results, it was found that the physicochemical properties of the shaped catalyst were largely recovered after the steam-assisted process. At the same time, as the powder catalyst could not react in the fixed bed reactor directly, we used the shaped HZSM- 5 catalyst by pressure as opposed to the others. After tableting molding HZSM-5 zeolite, the commercially-available zeolite, after the silicon aluminum extrusion process, and the shaped catalyst, after the steamassisted process, were tested in the MTA reaction at $400{ }^{\circ} \mathrm{C}$, $0.1 \mathrm{Ma}$ and WHSV $=1 \mathrm{~h}^{-1}$. Fig. 9 shows the yield of the liquid hydrocarbons as a function of the steam time for the three samples. EPHZ presented a poor performance with the shortest lifetime of $50 \mathrm{~h}$. Its initial yield was merely $16.41 \%$ and after $10 \mathrm{~h}$, the liquid hydrocarbons began to rapidly decline. After the steam-assisted crystallization process, SPHZ sample presented an improved catalytic performance compared to the commercially-available zeolite after the shaping progress. The zeolite after alkaline steam treatment showed a maximum yield that reached $24.4 \%$ and the catalytic lifetime was prolonged to 

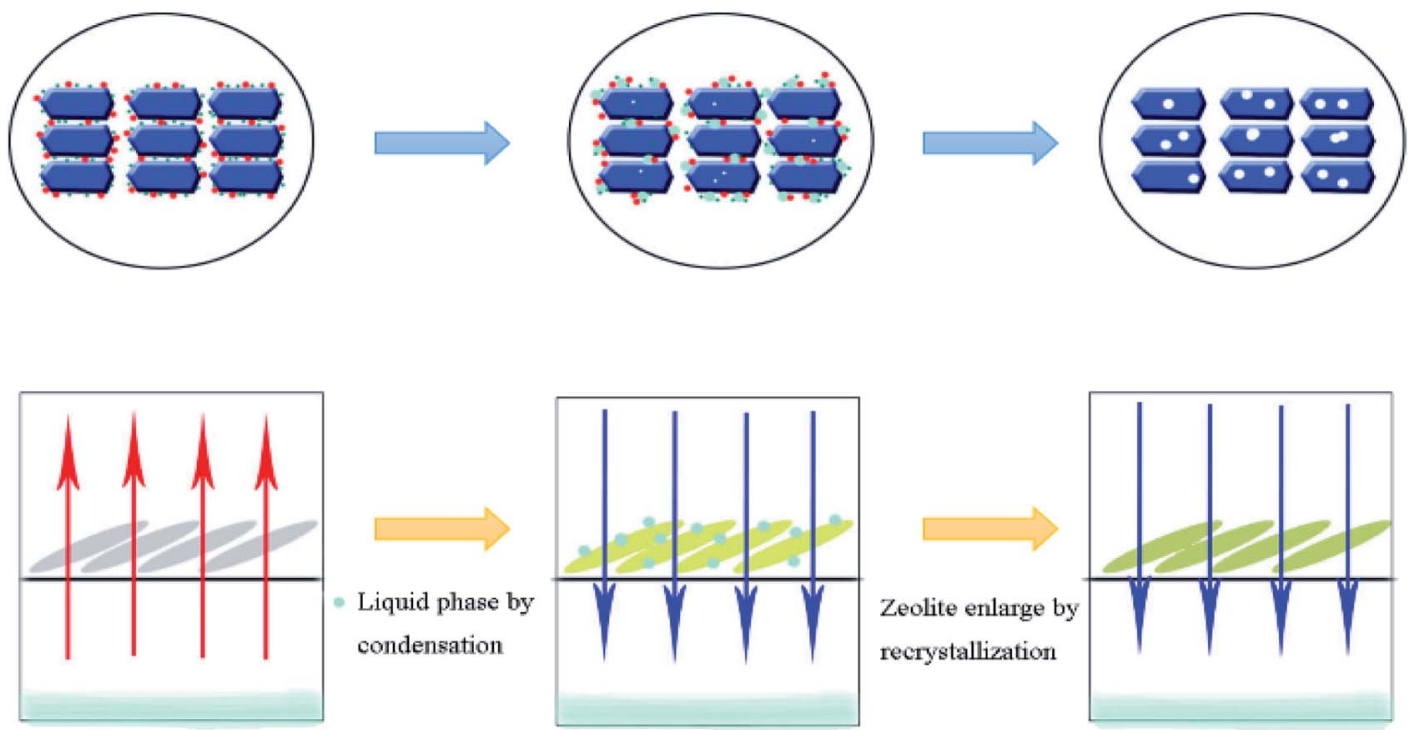

Fig. 8 The schematic re-crystallization process.

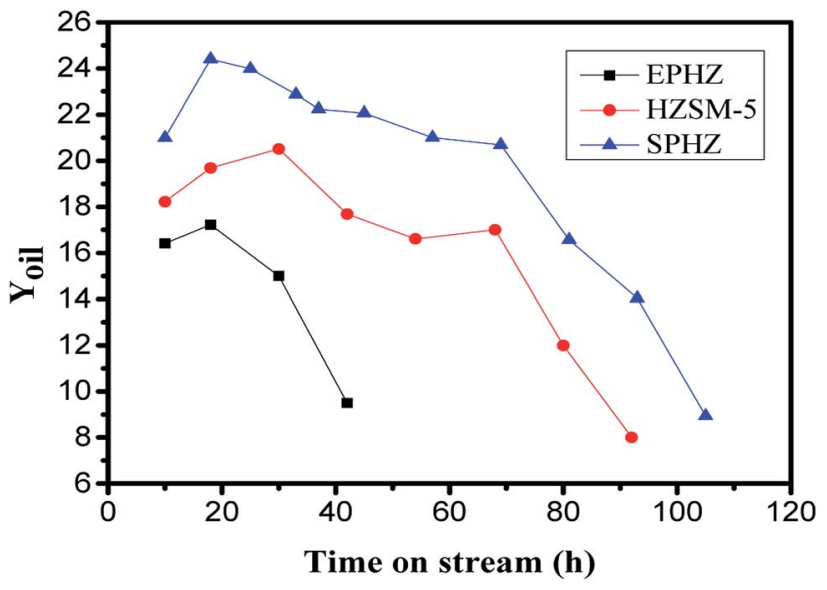

Fig. 9 Time course for the liquid hydrocarbons on $\mathrm{HZSM}-5, \mathrm{EPHZ}$ and SPHZ. Reaction conditions: $400^{\circ} \mathrm{C}, 0.1 \mathrm{MPa}, \mathrm{WHSV}=1 \mathrm{~h}^{-1}$.

105 h. In previous studies, ${ }^{23-25}$ the commercial ZSM-5 catalysts showed a poor catalytic performance in gasoline/aromatics syntheses with a short lifetime under $50 \mathrm{~h}$ and a low product yield. In this study, the maximum yield of HZSM-5 was $20.52 \%$ and the catalytic lifetime was $93 \mathrm{~h}$. Moreover, the selectivity towards C9, C10 and other large molecular weight aromatics in the products over SPHZ was much higher than EPHZ. This finding was mostly attributed to the elimination of external surface silicon adhesive passivation and the excellent porous shape-selectivity of SPHZ.

The coke on the above used HZSM-5, used EPHZ and used SPHZ were analyzed by TG. Since the molecular size of 1,3,5trimethylbenzene was close to the pore size of ZSM-5 zeolite with a boiling point of $165{ }^{\circ} \mathrm{C}$, it may have been the initial carbon deposition molecule for this series of ZSM-5 catalysts during the aromatic synthesis from methanol. ${ }^{26}$ As shown in Fig. 10, by careful observation, a slight weight loss existed below
$100{ }^{\circ} \mathrm{C}$, which corresponded to the volatilization of the moisture. Meanwhile, the decomposition of dissolved carbon ranged from $165-500{ }^{\circ} \mathrm{C}$ and the decomposition of insoluble carbon with a high molar ratio of $\mathrm{C} / \mathrm{H}$ was in the range of $500{ }^{\circ} \mathrm{C}$ to $750{ }^{\circ} \mathrm{C}$. The coke formation rate for used EPHZ was up to $1.7 \times$ $10^{-3} \mathrm{~g} \mathrm{~g}_{\text {cat }}{ }^{-1} \mathrm{~h}^{-1}$, while that for SPHZ was only $1.03 \times 10^{-3} \mathrm{~g}$ $\mathrm{g}_{\text {cat }}{ }^{-1} \mathrm{~h}^{-1}$ and HZSM-5 was $1.68 \times 10^{-3} \mathrm{~g} \mathrm{~g}_{\text {cat }}{ }^{-1} \mathrm{~h}^{-1}$. Moreover, the result of the $\mathrm{N}_{2}$ adsorption and XRD for SPHZ indicated that the porous structure of this catalyst was not destroyed during its recrystallization process. As a whole, SPHZ with a longer lifetime showed lower coke formation. Actually, the deposition rate was strongly affected by the structural and textural properties of the catalysts. The large external surface area indicated that the large pore opening was exposed to the outer surface, which was bound to shorten the diffusion path. The coke precursors easily migrated from the channel to the outer surface. For the HZSM-5 formed by tableting, there was no binder to influence the diffusion and the carbon deposits also easily diffused out of the pores.

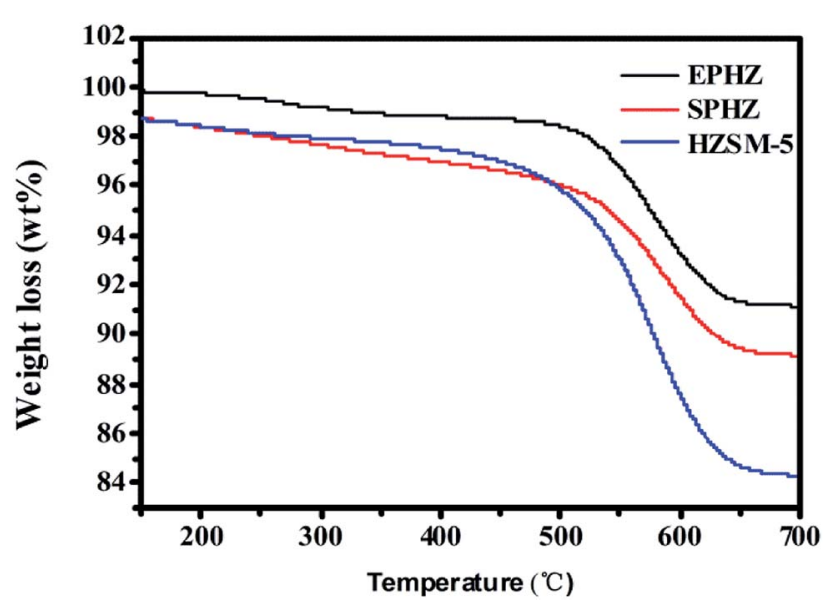

Fig. 10 TG curves of used HZSM-5, EPHZ and SPHZ. 
Table 2 Product distributions of the methanol transformation over the zeolites ${ }^{a}$

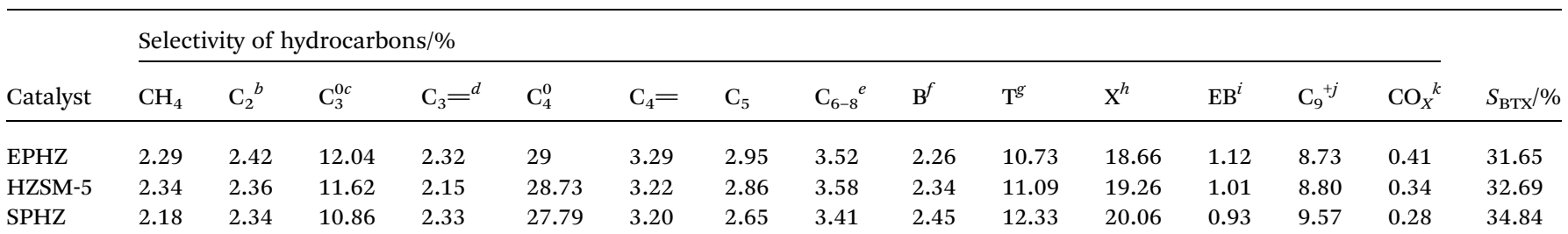

${ }^{a}$ Reaction conditions: $0.1 \mathrm{MPa}, 400{ }^{\circ} \mathrm{C}$, WHSV $=1 \mathrm{~h}^{-1} .{ }^{b} \mathrm{C}_{2}$ hydrocarbons. ${ }^{c} \mathrm{C}_{3}$ alkane. ${ }^{d} \mathrm{C}_{3}$ alkene. ${ }^{e} \mathrm{C}_{6-8}$ aliphatic hydrocarbons. ${ }^{f}$ Benzene. ${ }^{g}$ Toluene. ${ }^{h}$ Xylene. ${ }^{i}$ Ethylbenzene. ${ }^{j} \mathrm{C}_{9}$ and $\mathrm{C}_{9}{ }^{+}$hydrocarbons. ${ }^{k} \mathrm{CO}$ and $\mathrm{CO}_{2}$.

The most approved model for the hydrocarbon pool mechanism explains the selectivity for a particular shape in methanol during the hydrocarbon reaction. The most important feature of the hydrocarbon route is that methanol reacts with the hydrocarbon pool species through a series of steps to produce olefin and regenerated hydrocarbon over the course of the reaction cycle. We wanted to explore whether olefin was the basic unit of the aromatics. From Fig. 10, we observed that the aromatics increased when olefin was reduced. This also supported the aromatization in the propene experiments for $\mathrm{Cu} / \mathrm{ZSM}-5$ zeolite. The formation of the aromatic hydrocarbons using olefin as the basic unit was proven by the methanol feed with propylene. ${ }^{27}$ As presented in the Table 2, the BTX selectivity of SPHZ increased with time and reached a maximum of $34.84 \%$. HZSM-5 and EPHZ reached a maximum of $32.69 \%$ and $31.65 \%$, respectively. SPHZ exhibited a larger $\mathrm{C}_{9}{ }^{+}$than EPHZ due to the excess alkylation of the xylenes on external surface. It was difficult to generate in the channel because the trimethylbenzene diameter was $0.61 \mathrm{~nm}$ and it came directly from low-carbon xylene. Xylene was the main component in the product for EPHZ and SPHZ. The xylene content was similar to the total yield for benzene, toluene and $\mathrm{C}_{9}{ }^{+}$. The poor diffusion capability resulted in the formation of a higher number of C1-C5 hydrocarbons. Due to the steam assisted process, SPHZ exhibited an excellent diffusion capability. Therefore, SPHZ had less C1-C5 hydrocarbons than EPHZ. For HZSM-5 by tableting molding, the aromatic selectivity was higher than EPHZ due to the absence of the binder.

\section{Conclusions}

A longer life-span zeolite was prepared by a steam-assisted recrystallization process using an extrusion product as the raw material, and the prepared zeolite was tested via methanol aromatization. It was found that the pore structure and morphology resulted in a short catalyst lifetime of $50 \mathrm{~h}$. The main reason for the EPHZ sample exhibiting this short lifespan was that the binder covered the crystal and affected the mass transfer efficiency. After the alkali evaporation process for the shaped catalyst, the binder for the added aluminum source was successfully converted into a new grain catalyst phase. We observed by employing scanning electron microscopy that the binder around the catalyst almost disappeared after the alkali evaporation process. The catalytic lifetime was prolonged to
$105 \mathrm{~h}$. The large external surface area and appropriate acidity contributed together prolonged the catalyst lifetime of SPHZ. Alkali evaporation after the shaping process has great potential for methanol and aromatic reactions.

\section{Conflicts of interest}

There are no conflicts to declare.

\section{Acknowledgements}

This research was funded by Natural Science Foundation of China, grant number 21706178, 21978189; Natural Science Foundation of Shanxi Province, grant number 201801D221074, 201801D121058; China Postdoctoral Science Foundation 2019M651079. Authors also gratefully acknowledge the support and guidance of the 602 groups of teachers from Institute of Coal Chemistry, Chinese Academy of Sciences..

\section{References}

1 R. Khare and A. Bhan, J. Catal., 2015, 329, 218-228.

2 X. Sun, S. Mueller and H. Shi, J. Catal., 2014, 314, 21-31.

3 D. P. Serrano, J. M. Escola and R. Sanz, New J. Chem., 2016, 40, 4206-4216.

4 H. Schulz, Catal. Today, 2010, 154, 183-194.

5 G. Q. Zhang, T. Bai and T. F. Chen, Ind. Eng. Chem. Res., 2014, 53, 14932-14940.

6 M. Choi, H. S. Cho and R. Srivastava, Nat. Mater., 2006, 5, 718-723.

7 P. Wang, Y. Wang and M. J. Rood, CrystEngComm, 2015, 17, 3820-3828.

8 K. Shen, W. Qian and N. Wang, J. Mater. Chem. A, 2013, 1, 3272-3275.

9 N. L. Michels, S. Mitchell and J. Pérez-Ramírez, ACS Catal., 2014, 4, 2409-2417.

10 S. Y. Devyatkov, A. A. Zinnurova and A. Aho, Ind. Eng. Chem. Res., 2016, 55, 6595-6606.

11 J. Pérez-Ramírez, S. Mitchell and D. Verboekend, ChemCatChem, 2011, 3, 1731-1734.

12 S. Mitchell, N. L. Michels and J. Perez-Ramirez, Chem. Soc. Rev., 2013, 42, 6094-6112.

13 J. S. J. Hargreaves and A. L. Munnoch, Catal. Sci. Technol., 2013, 3, 1165-1171. 
14 L. Gueudré, M. Milina and S. Mitchell, Adv. Funct. Mater., 2014, 2, 209-219.

15 C. D. Chang, S. D. Hellring and J. N. Miale, J. Chem. Soc., Faraday Trans. 1, 1985, 8, 2215-2224.

16 J. Zhou, J. Teng and L. Ren, J. Catal., 2016, 340, 166-176.

17 P. C. Lai, C. H. Chen and H. Y. Hsu, RSC Adv., 2016, 6, 6736167371.

18 K. Shen, W. Qian and N. Wang, J. Mater. Chem. A, 2014, 2, 19797-19808.

19 J. C. Groen, T. Bach and U. Ziese, J. Am. Chem. Soc., 2005, 127, 10792-10793.

20 P. Sadeghpour and M. Haghighi, Particuology, 2015, 19, 6981.
21 W. Li, T. Ma and Y. Zhang, CrystEngComm, 2015, 17, 56805689.

22 K. Q. Shen, W. Z. Wang and N. Su, J. Mater. Chem. A, 2014, 2, 19797-19808.

23 C. Song, K. Liu, D. Zhang and S. Liu, Appl. Catal., A, 2014, 470, 15-23.

24 F. Schmidt, C. Hoffmann and F. Giordanino, J. Catal., 2013, 307, 238-245.

25 S. Fathi, M. Sohrabi and C. Falamaki, Fuel, 2014, 116, 529537.

26 J. H. Li, K. X. Tong and Z. W. Yuan, Catal. Sci. Technol., 2016, 6, 4802-4813.

27 M. Conte, J. A. Lopez-Sanchez and Q. He, Catal. Sci. Technol., 2012, 2, 105-112. 